\title{
Astragalus-based Formulation Qing Shu Yi Qi Tang
}

National Cancer Institute

\section{Source}

National Cancer Institute. Astragalus-based Formulation Qing Shu Yi Qi Tang. NCI

Thesaurus. Code C105616.

An herbal remedy containing Astragalus membranaceus, Panax ginseng, Atractylodes chinensis Koidz, Cimicifug a foetida, A. macrocephala Koidz, Alisma orientale Juzep, and Citrus reticulata Blanco, with potential immunomodulating, anti-oxidant and anticachexia activities. Upon oral consumption, the ing redients in this herbal supplement may modulate the activity of the immune system through a decrease in both the expression of nuclear factor-kappa B (NF-kappa B) and the production of pro-inflammatory cytokines such as interleukin-1 beta (II-1 b), IL-6, and tumor necrosis factor-alpha (TNFalpha). Increased levels of pro-inflammatory cytokines are correlated with decreased appetite and weight loss; thus, this herbal remedy may improve immune function, appetite and weight gain, which could prevent cachexia. 